FEDERAL

RESERVE

BANK of

ST. LOUIS
RESEARCH DIVISION

Working Paper Series

\title{
Policy and Welfare Effects of Within-Period Commitment
}

\author{
Fernando M. Martin
}

\author{
Working Paper 2011-031C \\ https://doi.org/10.20955/wp.2011.031
}

August 2013

\author{
FEDERAL RESERVE BANK OF ST. LOUIS \\ Research Division \\ P.O. Box 442 \\ St. Louis, MO 63166
}

The views expressed are those of the individual authors and do not necessarily reflect official positions of the Federal Reserve Bank of St. Louis, the Federal Reserve System, or the Board of Governors.

Federal Reserve Bank of St. Louis Working Papers are preliminary materials circulated to stimulate discussion and critical comment. References in publications to Federal Reserve Bank of St. Louis Working Papers (other than an acknowledgment that the writer has had access to unpublished material) should be cleared with the author or authors. 


\title{
Policy and Welfare Effects of Within-Period Commitment
}

\author{
Fernando M. Martin* \\ Federal Reserve Bank of St. Louis and Simon Fraser University
}

July 8,2013

\begin{abstract}
Consider the problem of a benevolent government that needs to finance the provision of a public good with distortionary taxes and cannot commit to policies beyond the current period. In such a case, public expenditure is inefficiently low. If the government further loses the ability to set tax rates before production in the period takes place, then it will not internalize how its policy choices distort current factor markets. Thus, to counterbalance the costs of future distortions, it increases public good provision. For a calibrated economy, removing within-period commitment implies a welfare gain worth half-a-percent of yearly consumption. A similar gain can be obtained, if instead, capital depreciation were allowed to be fully deducted from taxable income.
\end{abstract}

Keywords: fiscal policy; time-consistency; lack of commitment; Markov-perfect equilibrium.

JEL classification: E61, E62

${ }^{*}$ Email: fernando.m.martin@stls.frb.org. I would like to thank two anonymous referees and the Associate Editor for helpful comments. This paper previously circulated under the title "Tax Structure and Time-Consistent Policy". The views expressed in this paper do not necessarily reflect official positions of the Federal Reserve Bank of St. Louis, the Federal Reserve System, or the Board of Governors. 


\section{Introduction}

In modern developed economies, fiscal budgets are typically proposed and approved on an annual basis. This suggests the presence of institutions that endow the government with the ability to "commit" to specific policies, at least for a certain period of time. For example, in the U.S., the President submits a federal budget to Congress for approval before the start of the fiscal year. In addition, both chambers of Congress are required to submit concurrent budget resolutions. There are, however, mechanisms that allow the government to exercise ex-post discretion, such as supplemental appropriation and emergency bills. These may be so significant or frequent that they render the idea of commitment as largely illusory.

Whether some commitment - or a mechanism that substitutes for it - is available or not depends on the institutional design of an economy. Institutions may be strong enough to make policy announcements, such as an approved budget, binding obligations. ${ }^{1}$ This strength may be eroded over time by continually exercising ex-post discretion. Similarly, times of great stress - such as a national emergency or a financial crisis - may induce politicians to implement bolder changes to preannounced policy. Recent examples in the U.S. include the several tax provisions and supplemental spending enacted in response to the 2001 and 2007-09 recessions. $^{2}$

In this paper, I study how the degree of commitment affects government policy and general welfare. Specifically, I analyze the determination of government policy in a standard neoclassical growth model, where a benevolent government provides a public good financed with income taxes. Critically, the government cannot commit to policy choices in future periods, and mechanisms that could substitute for commitment (e.g., reputation) are not operative. Under these assumptions, I consider two alternative institutional scenarios. In the first case, following Klein et al. (2008), the government can commit to policies announced at the beginning of each period, i.e., has access to within-period commitment. In the second case, the government lacks within-period commitment and chooses period policy at the same time as factor markets operate and production takes place. After period policy is revealed, agents makes their consumption and savings decisions. In the context of the neoclassical growth model, the latter timing of events implies that the tax base and tax rate are determined simultaneously. The critical difference between the two institutional regimes is that, when the government lacks within-period commitment, it does not internalize the distortionary effect of taxation on the current labor supply or, equivalently, the consumption-leisure choice. $^{3}$

When the government has within-period commitment, it smoothes current and future policy distortions. Current distortions are directly created by current policy choices. Future distortions are created by future policy, and therefore, induced by current capital accumulation, which in turn is affected by both current and future policy. Since taxes are distortionary, a standard result in

\footnotetext{
${ }^{1}$ For example, Bohn and Inman (1996) show that, for U.S. states, more stringent balanced-budget rules have a measurable impact on budget deficits.

${ }^{2} \mathrm{~A}$ case in point, the difference between the actual U.S. deficit in the fiscal year 2009 and the figure projected in the original budget proposal was one trillion dollars. See Taylor (2011) for a discussion on the recent fiscal stimulus packages.

${ }^{3}$ Note that, within the context of this paper, there is no corresponding distortion on capital since it is supplied inelastically within a period. Capital accumulation is however distorted by future income taxes. In more general environments, income taxes can also distort the current supply of capital. One example is to allow for variable capital utilization as in Greenwood et al. (1988); see Zhu (1995) and Martin (2010) for applications.
} 
this type of setting is an inefficiently low provision of public goods - see Klein et al. (2008) and Martin (2010). If the government loses its ability to commit within the period, then it no longer internalizes the distortion created on current labor supply, which leads it to increase the provision of public goods, to counterbalance the costs of future distortions. This results in higher tax rates.

For an economy calibrated to the postwar U.S., losing within-period commitment is welfare improving. That is, the gains from a more efficient supply of public goods more than compensates the costs of higher tax rates. The welfare gain is equivalent to a permanent increase in private consumption by $0.52 \%$. Clearly, these gains depend on how far we are from the efficient supply of public goods before the regime changes. Economies where the optimal size of government is smaller, report lower improvements from losing within-period commitment.

The welfare properties of within-period commitment are closely tied to deductions on taxable income. In particular, the capital depreciation allowance directly affects the tax base, and thus, has significant implications on the magnitude of policy distortions and how they are managed by the government. I show that a similar welfare gain can be obtained if, instead of losing commitment, the government increases the capital depreciation tax deduction from the post-war average of about $43 \%$ all the way up to $100 \%$. This gain arises because a lower taxable income translates into a smaller intertemporal savings distortion.

Given the results described in the preceding paragraphs, one may be inclined to conclude that a desirable institutional reform would involve both removing the government's ability to commit within a period and increasing the capital depreciation allowance to $100 \%$. This would be incorrect in some cases. For the benchmark calibration, such a reform would actually lead to a welfare loss worth about $2 \%$ of consumption. The combined effects of a higher incentive to tax and a lower tax base result in distortions large enough to overcome the gains from higher public good provision.

The way I model lack of within-period commitment, as described above, departs from previous work. Most notably, Ortigueira (2006), building on earlier work by Turnovsky and Brock (1980) and Judd (1998), assumes that government policy is implemented at the same time as households choose consumption, leaving savings to be determined residually to satisfy their budget constraint. There is an analogous case, where instead, consumption is left as a residual. One could raise several conceptual concerns on this earlier approach. First, the modeler has to arbitrarily assume whether consumption or savings are determined residually, once government policy is known. Second, the welfare implications of institutional reform are necessarily vague; e.g., if the government loses the ability to commit within a period, which of the two cases with lack of within-period commitment arises? Finally, the approach implicitly assumes that households commit to a spending or savings decision before taxes are known, instead of waiting for policy to be revealed before actions are finalized. It appears more plausible that households are able to defer at least part of their consumption and investment decisions for after tax rates are known.

Some recent studies on fiscal policy with limited commitment offer alternative takes on the timing of government actions. Klein and Ríos-Rull (2003) assume the current government decides on today's labor taxes and tomorrow's capital taxes. Ortigueira et al. (2012) assume within-period commitment for incomes taxes, but not for debt issuance. Debortoli and Nunes (2010) propose an intermediate approach to intertemporal commitment, by modeling an economy in which the opportunity to re-optimize policy arrives stochastically. If we consider the benchmark case of a government with access to within-period commitment only, Debortoli and Nunes study the effects 
of increasing commitment, whereas this paper, same as Ortigueira's, analyzes the effects of reducing it.

The paper is organized as follows. Section 2 describes the environment and characterizes government policy for the two cases considered. Section 3 conducts the numerical evaluation of the model, including policy experiments and alternative specifications. Section 4 concludes. The appendix covers alternative implementations of lack of within-period commitment, as described above.

\section{The Model}

\section{$2.1 \quad$ Environment}

Consider an economy populated by a continuum of identical households. Time is discrete and indexed by $t=0,1, \ldots, \infty$. Households are endowed with one unit of time per period for work and leisure, and may accumulate capital, which depreciates at rate $\delta \in[0,1]$ every period.

Lifetime utility of a representative household is given by

$$
\sum_{t=0}^{\infty} \beta^{t} u\left(c_{t}, 1-n_{t}, G_{t}\right),
$$

where $\beta \in(0,1)$ is the discount factor, $c$ is consumption of an homogenous private good, $n$ is labor and $G$ is consumption of a public good. The instantaneous utility function $u$ is continuously differentiable, strictly increasing and strictly concave in all its arguments.

Firms maximize profits and use capital and labor as inputs. The production function is constant returns to scale and given by $F(k, n)$, where $F$ is differentiable, strictly concave and strictly increasing in both arguments. Factor markets are perfectly competitive.

The government supplies the public good, financed with revenue from taxes $\tau$ on household income. As in Ortigueira (2006), Klein et al. (2008) and Martin (2010), among many others, there is no government debt. This is an extreme version of limited commitment, in which the government can renege, with impunity, on all past promises, including debt obligations. In such a case, private agents would not buy public debt at any price, although it is possible that the government may want to accumulate assets - see Klein et al. (2008) for further discussion. ${ }^{4}$

Using upper-case letters to denote aggregate allocations, the government period budget constraint is

$$
G_{t}=\tau_{t}\left(F\left(K_{t}, N_{t}\right)-\theta \delta K_{t}\right)
$$

where $\theta \in[0,1]$ is the capital depreciation allowance in taxable income. Typically, taxation models assume this allowance to be either zero or one. Actual tax codes only allow some types of capital depreciation to be deducted and then according to specific schedules, which may not correspond to

\footnotetext{
${ }^{4}$ In addition, the balanced-budget assumption simplifies the government's problem considerably. As we shall see below, solving for equilibrium government policy involves finding a fixed point in policy functions, a problem that increases significantly in complexity as we add endogenous state variables.
} 
the actual "economic" depreciation. As we shall see below, the value of $\theta$ has an important effect on equilibrium policy since it affects the tax base. ${ }^{5}$

Given factor prices $r_{t}$ and $w_{t}$, and income taxes $\tau_{t}$, the budget constraint of the household is

$$
c_{t}+k_{t+1}=\left(1-\tau_{t}\right)\left(\left(r_{t}-\theta \delta\right) k_{t}+w_{t} n_{t}\right)+(1-(1-\theta) \delta) k_{t} .
$$

For any given sequence of factor prices and government policy, $\left\{r_{t}, w_{t}, \tau_{t}, G_{t}\right\}_{t=0}^{\infty}$, and initial capital $k_{0}$, household behavior can be characterized by a sequence $\left\{c_{t}, k_{t+1}, n_{t}\right\}_{t=0}^{\infty}$ that satisfies (1) and the familiar first-order conditions from the household's optimization problem:

$$
\begin{aligned}
-u_{c}\left(c_{t}, 1-n_{t}, G_{t}\right)+\beta u_{c}\left(c_{t+1}, 1-n_{t+1}, G_{t+1}\right)\left[1-(1-\theta) \delta+\left(1-\tau_{t+1}\right)\left(r_{t+1}-\theta \delta\right)\right] & =0 \\
u_{c}\left(c_{t}, 1-n_{t}, G_{t}\right)\left(1-\tau_{t}\right) w_{t}-u_{\ell}\left(c_{t}, 1-n_{t}, G_{t}\right) & =0
\end{aligned}
$$

where $u_{c}$ and $u_{\ell}$ are the derivatives of the utility function with respect to consumption and leisure, respectively.

\subsection{Competitive Equilibrium}

In a competitive equilibrium, factor prices are equal to their respective marginal products. Thus, $r_{t}=F_{K}\left(K_{t}, N_{t}\right)$ and $w_{t}=F_{N}\left(K_{t}, N_{t}\right)$, where $F_{i}$ is the derivative of $F(K, N)$ with respect to argument $i=\{K, N\}$. Consistency dictates $c_{t}=C_{t}, k_{t+1}=K_{t+1}$ and $n_{t}=N_{t}$. From the government budget constraint, we can write taxes as

$$
\tau_{t}=\frac{G_{t}}{F\left(K_{t}, N_{t}\right)-\theta \delta K_{t}},
$$

while the resource constraint specifies aggregate consumption

$$
C_{t}=F\left(K_{t}, N_{t}\right)+(1-\delta) K_{t}-K_{t+1}-G_{t} .
$$

Using these equilibrium conditions, (2) and (3) become

$$
\begin{array}{r}
-u_{c}\left(F\left(K_{t}, N_{t}\right)+(1-\delta) K_{t}-K_{t+1}-G_{t}, 1-N_{t}, G_{t}\right) \\
+u_{c}\left(F\left(K_{t+1}, N_{t+1}\right)+(1-\delta) K_{t+1}-K_{t+2}-G_{t+1}, 1-N_{t+1}, G_{t+1}\right) \\
\times \beta\left\{1-(1-\theta) \delta+\left[1-\frac{G_{t+1}}{F\left(K_{t+1}, N_{t+1}\right)-\theta \delta K_{t+1}}\right]\left(F_{K}\left(K_{t+1}, N_{t+1}\right)-\theta \delta\right)\right\}=0 \\
u_{c}\left(F\left(K_{t}, N_{t}\right)+(1-\delta) K_{t}-K_{t+1}-G_{t}, 1-N_{t}, G_{t}\right)\left[1-\frac{G_{t}}{F\left(K_{t}, N_{t}\right)-\theta \delta K_{t+1}}\right] F_{N}\left(K_{t}, N_{t}\right) \\
-u_{\ell}\left(F\left(K_{t}, N_{t}\right)+(1-\delta) K_{t}-K_{t+1}-G_{t}, 1-N_{t}, G_{t}\right)=0,
\end{array}
$$

which can be written compactly as

$$
\begin{aligned}
\Phi\left(K_{t}, K_{t+1}, K_{t+2}, N_{t}, N_{t+1}, G_{t}, G_{t+1}\right) & =0 \\
\Psi\left(K_{t}, K_{t+1}, N_{t}, G_{t}\right) & =0 .
\end{aligned}
$$

\footnotetext{
${ }^{5}$ See Guo and Lansing (1997) and Guo and Lansing (1999) for an analysis of the effects of the depreciation allowance in a standard Ramsey model of optimal taxation. See also Pecorino (1993) and Stokey and Rebelo (1995) for how tax structure affects growth.
} 
Given initial aggregate capital $K_{0}$ and a sequence of public expenditure $\left\{G_{t}\right\}_{t=0}^{\infty}$, a competitive equilibrium is characterized by a sequence $\left\{K_{t+1}, N_{t}\right\}_{t=0}^{\infty}$ that satisfies (4) and (5) for all $t=$ $0,1, \ldots, \infty$. Below, we shall study how government expenditure is determined.

\subsection{Government Policy}

Assume the government is benevolent but cannot commit to policies beyond the current period. Furthermore, focus on the case when governments base their decisions solely on fundamentals. ${ }^{6}$ Thus, let us analyze Markov-perfect equilibria, i.e., equilibria where aggregate household behavior and government policy depend only on the aggregate capital stock. Given this approach, I will formulate the problem of the government recursively. ${ }^{7}$

The limited commitment assumption still leaves open the question of how much commitment the government has within a period. For example, can the government commit to policy announcements made at the beginning of the period or does it lack even this small amount of commitment? If so, how do events unravel in a period?

The recent literature on Markov-perfect taxation has focused on two cases. For example, Klein et al. (2008), Martin (2010) and Azzimonti et al. (2009) consider the case when the government can commit to policy announcements within a period. Ortigueira (2006), based on earlier work by Turnovsky and Brock (1980) and Judd (1998), proposes an alternative environment where households choose consumption and labor at the same time as the government chooses the tax rate, and thus, savings are left as a residual to satisfy the household's budget constraint. There is a similar case one could analyze in which, instead, consumption is left as a residual - see Appendix C. One drawback with this approach to modelling lack of within-period commitment, is that one has to arbitrarily assume whether consumption or savings are determined residually, once government policy is known. Furthermore, why would households commit to all their spending or savings decision before taxes are known, instead of waiting for policy to be revealed before actions are finalized?

In this paper, I consider two cases to analyze the effects on policy and welfare of within-period commitment. In the first environment, following Klein et al. (2008), the government has the ability to commit to a policy at the beginning of the period. I.e., it has within-period commitment. Thus, $G$ and by implication $\tau$, are determined at the beginning of each period, before households make any decisions. In this case, the government fully internalizes the effects of its policy choices on the current decisions of households.

In the second environment, the government chooses policy at the same time as factor markets operate. In other words, the tax rate and the tax base are determined simultaneously. Subsequently, households decide on consumption and savings. In this case, the government does not internalize the effects of its policy choices on factor markets and production in the current period. In particular, given that capital is supplied inelastically, the government takes the labor supply as given. This scenario avoids making an arbitrary choice about whether consumption or savings are determined

\footnotetext{
${ }^{6}$ In the Appendix, in order to compare the different tax regimes analytically, I will further refine the equilibrium concept to include only equilibria which are the limit of finite horizon equilibria. This requirement alone rules out the type of equilibria studied by Chari and Kehoe (1990) and Phelan and Stacchetti (2001), among others, which require an infinite horizon.

${ }^{7}$ See Maskin and Tirole (2001) for a definition and justification of Markov-perfect equilibria.
} 
residually, since both are chosen after tax rates are announced, while it preserves the notion that governments can wait until some economic decisions are made, before setting a policy for the period. Note that an equivalent formulation consists of having the government set policy after factor markets close, but before goods markets open.

Given the assumptions on the environment, from the point of view of an individual household, there is no distinction between observing the actual tax rate for the period and (correctly) anticipating it. Thus, in both institutional scenarios, household's behavior is characterized by (4) and (5). The difference lies in which households' responses to current policy will be internalized by the government.

\subsection{Within-period commitment: "government-moves-first"}

Consider first the case when the government commits to policy announcements within a period, which corresponds to the environment analyzed by Klein et al. (2008). When the government makes its announcement it needs to take into account how household will react in the current period, i.e., how consumption, labor and savings decisions will be affected by current taxes, given anticipated future policy.

Adopting what is known in the optimal taxation literature as the primal approach, we can write the government's problem as choosing current $K^{\prime}, N$ and $G$, subject to households behaving competitively, as characterized by (4) and (5), and given future anticipated policy $\mathcal{G}(K)$, which in turn, implements household behavior characterized by $\mathcal{N}(K)$ and $\mathcal{H}(K)$, and provides net present value utility $\mathcal{V}(K)$.

The problem of the government can be written as

$$
\max _{K^{\prime}, N, G} u\left(F(K, N)+(1-\delta) K-G-K^{\prime}, 1-N, G\right)+\beta \mathcal{V}\left(K^{\prime}\right)
$$

subject to

$$
\begin{aligned}
\Phi\left(K, K^{\prime}, \mathcal{H}\left(K^{\prime}\right), N, \mathcal{N}\left(K^{\prime}\right), G, \mathcal{G}\left(K^{\prime}\right)\right) & =0 \\
\Psi\left(K, K^{\prime}, N, G\right) & =0 .
\end{aligned}
$$

Definition 1 When the government is endowed with within-period commitment, a Markov-perfect equilibrium is a set of functions $\{\mathcal{H}, \mathcal{N}, \mathcal{G}, \mathcal{V}\}: \mathbb{R}_{+} \rightarrow \mathbb{R}_{+} \times[0,1] \times \mathbb{R}_{+} \times \mathbb{R}$, such that for all $K>0$ :

(i) $\{\mathcal{H}(K), \mathcal{N}(K), \mathcal{G}(K)\}=\operatorname{argmax}_{\left\{K^{\prime}, N, G\right\}} u\left(F(K, N)+(1-\delta) K-G-K^{\prime}, 1-N, G\right)+\beta \mathcal{V}\left(K^{\prime}\right)$ subject to (6) and (7);

(ii) $\mathcal{V}(K)=u(F(K, \mathcal{N}(K))+(1-\delta) K-\mathcal{H}(K)-\mathcal{G}(K), 1-\mathcal{N}(K), \mathcal{G}(K))+\beta \mathcal{V}(\mathcal{H}(K))$

Assuming an equilibrium with differentiable policy functions exists, we can further characterize it using the first-order conditions of the government's problem. ${ }^{8}$ For clarity of exposition, let us

\footnotetext{
${ }^{8}$ Appendix B shows that a differentiable equilibrium exists under specific assumptions. Among others, Krusell and Smith (2003) and Martin (2009) report coexistence of differentiable and non-differentiable Markov-perfect equilibria. Ortigueira et al. (2012) report multiplicity of differentiable Markov-perfect equilibria. Krusell et al. (2006) analyze an economy where the fundamental equilibrium (the limit of finite horizon equilibria) is non-differentiable.
} 
switch to short-hand notation, i.e., ignoring the arguments of functions. With associated Lagrange multipliers $\lambda$ and $\mu$ on the two constraints of the problem, the first-order conditions are

$$
\begin{array}{r}
-u_{c}+\beta \mathcal{V}_{K}^{\prime}+\lambda \Sigma_{K^{\prime}}+\mu \Psi_{K^{\prime}}=0 \\
u_{c} F_{N}-u_{\ell}+\lambda \Phi_{N}+\mu \Psi_{N}=0 \\
-u_{c}+u_{g}+\lambda \Phi_{G}+\mu \Psi_{G}=0
\end{array}
$$

where $\Sigma_{K^{\prime}} \equiv \Phi_{K^{\prime}}+\Phi_{K^{\prime \prime}} \mathcal{H}_{K}^{\prime}+\Phi_{N^{\prime}} \mathcal{N}_{K}^{\prime}+\Phi_{G^{\prime}} \mathcal{G}_{K}^{\prime}$.

We can use the last two equations above to solve for the Lagrange multipliers:

$$
\begin{aligned}
\lambda & =\frac{\Psi_{N}\left(u_{g}-u_{c}\right)-\Psi_{G}\left(u_{c} F_{N}-u_{\ell}\right)}{\Phi_{N} \Psi_{G}-\Phi_{G} \Psi_{N}} \\
\mu & =-\frac{\Phi_{N}\left(u_{g}-u_{c}\right)-\Phi_{G}\left(u_{c} F_{N}-u_{\ell}\right)}{\Phi_{N} \Psi_{G}-\Phi_{G} \Psi_{N}} .
\end{aligned}
$$

The envelope condition implies (see Appendix A for derivation):

$$
\mathcal{V}_{K}=u_{c}\left(F_{K}+1-\delta\right)+\lambda \Phi_{K}+\mu \Psi_{K}
$$

We thus get (arranged by wedges)

$$
\begin{aligned}
-u_{c}+\beta u_{c}^{\prime}\left(F_{K}^{\prime}+1-\delta\right) & +\frac{\left(u_{c} F_{n}-u_{\ell}\right)\left(\Phi_{G} \Psi_{K^{\prime}}-\Psi_{G} \Sigma_{K^{\prime}}\right)}{\Phi_{N} \Psi_{G}-\Phi_{G} \Psi_{N}}-\frac{\left(u_{g}-u_{c}\right)\left(\Phi_{N} \Psi_{K^{\prime}}-\Psi_{N} \Sigma_{K^{\prime}}\right)}{\Phi_{N} \Psi_{G}-\Phi_{G} \Psi_{N}} \\
& +\frac{\beta\left(u_{c}^{\prime} F_{n}^{\prime}-u_{\ell}^{\prime}\right)\left(\Phi_{G}^{\prime} \Psi_{K}^{\prime}-\Psi_{G}^{\prime} \Phi_{K}^{\prime}\right)}{\Phi_{N}^{\prime} \Psi_{G}^{\prime}-\Phi_{G}^{\prime} \Psi_{N}^{\prime}}-\frac{\beta\left(u_{g}^{\prime}-u_{c}^{\prime}\right)\left(\Phi_{N}^{\prime} \Psi_{K}^{\prime}-\Psi_{N}^{\prime} \Phi_{K}^{\prime}\right)}{\Phi_{N}^{\prime} \Psi_{G}^{\prime}-\Phi_{G}^{\prime} \Psi_{N}^{\prime}}=0 .
\end{aligned}
$$

Since this equation contains the derivatives of policy functions, it is typically called a Generalized Euler Equation or GEE.

There are five policy wedges the government is internalizing. Each of these would be equal to zero at the first-best allocation (which would be implemented if lump-sum taxes were available). Two wedges are directly created by current policy, while the other three are created by future policy and thus, depend on the effects of current and future policy on capital accumulation.

First, we have the current distortions created by the use of linear taxation: $u_{c} F_{N}-u_{\ell}$ and $u_{g}-u_{c}$. The former is the consumption-leisure wedge and the latter is the inefficiency in public good provision. These two wedges cannot be eliminated simultaneously: public goods are created with an inefficient transformation of private goods (linear taxes) and this same technology reduces the incentives to supply labor. Second, capital accumulation affects policy in the following period. Thus, there are three additional wedges the current government is internalizing: $u_{c}^{\prime} F_{N}^{\prime}-u_{\ell}^{\prime}, u_{g}^{\prime}-u_{c}^{\prime}$ and $-u_{c}+\beta u_{c}^{\prime}\left(F_{K}^{\prime}+1-\delta\right)$. The last wedge is the effect of future income taxes on current capital accumulation. The current government cannot directly control any of these three wedges, but can affect their magnitude by controlling the effects of its own policies on current savings.

Note that there is no wedge created by current policy on capital accumulation, since from the perspective of the current government capital is supplied inelastically. One way to make the government view the current taxation of capital as distortionary, is to allow for variable capital 
utilization. In this case, one could in addition grant government the power to tax capital and labor income differently. As shown in Martin (2010), for an economy calibrated to postwar U.S. (with a similar parameterization to the one assumed in Section 3), steady state capital and labor tax rates are roughly the same.

\subsection{Lack of within-period commitment: "simultaneous actions"}

Suppose now that the government cannot commit to an announcement within the period. Specifically, income taxes are set at the same time as factor markets operate and production takes place.

In this scenario, the current government does not internalize the effects its policy choices have on current labor decisions. Unlike the previous case, the government now takes $N=\mathcal{N}(K)$ as given. Thus, we can write the government's problem as choosing $K^{\prime}$ and $G$, subject to households behaving competitively, as characterized by (4) and $\mathcal{N}(K)$, given future anticipated policy $\mathcal{G}(K)$, which in turn, implements future household behavior characterized by $\mathcal{N}(K)$ and $\mathcal{H}(K)$, and provides net present value utility $\mathcal{V}(K)$. Note that (5) is no longer a constraint in the government's problem-it has been replaced by the function $\mathcal{N}(K)$.

The problem of the government can be written as

$$
\max _{K^{\prime}, G} u\left(F(K, \mathcal{N}(K))+(1-\delta) K-G-K^{\prime}, 1-\mathcal{N}(K), G\right)+\beta \mathcal{V}\left(K^{\prime}\right)
$$

subject to

$$
\Phi\left(K, K^{\prime}, \mathcal{H}\left(K^{\prime}\right), \mathcal{N}(K), \mathcal{N}\left(K^{\prime}\right), G, \mathcal{G}\left(K^{\prime}\right)\right)=0
$$

Definition 2 When the government lacks within-period commitment, a Markov-perfect equilibrium is a set of functions $\{\mathcal{H}, \mathcal{N}, \mathcal{G}, \mathcal{V}\}: \mathbb{R}_{+} \rightarrow \mathbb{R}_{+} \times[0,1] \times \mathbb{R}_{+} \times \mathbb{R}$, such that for all $K>0$ :

(i) $\{\mathcal{H}(K), \mathcal{G}(K)\}=\operatorname{argmax}_{\left\{K^{\prime}, G\right\}} u\left(F(K, \mathcal{N}(K))+(1-\delta) K-G-K^{\prime}, 1-\mathcal{N}(K), G\right)+\beta \mathcal{V}\left(K^{\prime}\right)$ subject to (9);

(ii) $\Psi(K, \mathcal{H}(K), \mathcal{N}(K), \mathcal{G}(K))=0$;

(iii) $\mathcal{V}(K)=u(F(K, \mathcal{N}(K))+(1-\delta) K-\mathcal{H}(K)-\mathcal{G}(K), 1-\mathcal{N}(K), \mathcal{G}(K))+\beta \mathcal{V}(\mathcal{H}(K))$.

With associated Lagrange multiplier $\lambda$ on the constraint of the government's problem, the first-order conditions are

$$
\begin{aligned}
-u_{c}+\beta \mathcal{V}_{K}^{\prime}+\lambda \Sigma_{K^{\prime}} & =0 \\
-u_{c}+u_{g}+\lambda \Phi_{G} & =0
\end{aligned}
$$

where $\Sigma_{K^{\prime}} \equiv \Phi_{K^{\prime}}+\Phi_{K^{\prime \prime}} \mathcal{H}_{K}^{\prime}+\Phi_{N^{\prime}} \mathcal{N}_{K}^{\prime}+\Phi_{G^{\prime}} \mathcal{G}_{K}^{\prime}$, as defined above. From the second equation, we get an expression for the Lagrange multiplier

$$
\lambda=-\frac{\left(u_{g}-u_{c}\right)}{\Phi_{G}} .
$$


The envelope condition implies (see Appendix A for derivation):

$$
\mathcal{V}_{K}=u_{c}\left(F_{K}+1-\delta\right)+\left(u_{c} F_{N}-u_{\ell}\right) \mathcal{N}_{K}+\lambda\left(\Phi_{K}+\Phi_{N} \mathcal{N}_{K}\right)
$$

and so the GEE becomes

$$
-u_{c}+\beta u_{c}^{\prime}\left(F_{K}^{\prime}+1-\delta\right)+\beta\left(u_{c}^{\prime} F_{N}^{\prime}-u_{\ell}^{\prime}\right) \mathcal{N}_{K}^{\prime}-\frac{\left(u_{g}-u_{c}\right) \Sigma_{K^{\prime}}}{\Phi_{G}}-\frac{\beta\left(u_{g}^{\prime}-u_{c}^{\prime}\right)\left(\Phi_{K}^{\prime}+\Phi_{N}^{\prime} \mathcal{N}_{K}^{\prime}\right)}{\Phi_{G}^{\prime}}=0
$$

In this case, the government is internalizing four wedges, which is one less than in the case with within-period commitment. The missing distortion is $u_{c} F_{N}-u_{\ell}$, since the government decides on policy at the same time as factor markets operate and therefore, does not internalize the effects of current policy on the labor supply. Note however, that the current government does internalize the effect of policy on tomorrow's labor supply, i.e., the wedge $u_{c}^{\prime} F_{N}^{\prime}-u_{\ell}^{\prime}$. The reason is that the government can indirectly affect this future distortion, by how its policy actions affect current capital accumulation.

In contrast to the previous case, allowing for variable capital utilization in an economy without within-period commitment would not make the government view the taxation of current capital income as distortionary. The reason is the same as to why the government does not internalize the distortion in the labor supply: policy is chosen while factor markets operate. Hence, the distribution of the tax burden between capital and labor income cannot be pinned down. In other words, regardless of whether we allow for variable capital utilization or not, granting government the power to tax capital and labor income differently would lead to indeterminate tax rates. ${ }^{9}$ One solution would be to tax both types of income uniformly, as assumed here.

\section{Numerical Evaluation}

\subsection{Calibration}

Consider the following functional forms:

$$
\begin{aligned}
u(c, 1-n, G) & =\alpha\left(1-\alpha_{g}\right) \ln c+(1-\alpha)\left(1-\alpha_{g}\right) \ln (1-n)+\alpha_{g} \ln G \\
F(K, N) & =K^{\gamma} N^{1-\gamma},
\end{aligned}
$$

with $\alpha, \alpha_{g}, \gamma \in(0,1)$. Period length is equal to a year. The calibration is borrowed from Klein et al. (2008), to facilitate comparisons to that paper and subsequent work that adopted the same parameterization - see Table 1. Throughout the paper, let the benchmark case be the environment with within-period commitment, which for benchmark parameters roughly matches the post-war U.S. economy. ${ }^{10}$ To calibrate $\theta$, which was implicitly set to 1 in Klein et al. (2008), I use "Corporate Capital Consumption Allowances" from the National Income and Product Accounts (see NIPA

\footnotetext{
${ }^{9}$ Note however, that the current government would internalize future capital and labor tax rates differently, as only capital taxes create an intertemporal distortion.

${ }^{10}$ Target statistics for the environment with within-period commitment are standard: a capital-output ratio of 2.5 (where capital is defined as private capital plus consumer durables), private consumption roughly three times public goods provision, a share of capital income in total income of about one-third, government expenditure to GDP of $20 \%$ and hours worked about one quarter of discretionary time.
} 
Table 6.22). The coefficient of depreciation allowance is obtained from dividing corporate capital consumption allowances by the total depreciation of private capital and consumer durables. The average between 1962 and 2006 is $42 \%$.

Table 1: Benchmark Parameters

\begin{tabular}{|l|c|c|c|c|c|c|}
\hline Parameter & $\alpha$ & $\alpha_{g}$ & $\beta$ & $\gamma$ & $\delta$ & $\theta$ \\
\hline Value & 0.300 & 0.130 & 0.960 & 0.360 & 0.080 & 0.420 \\
\hline
\end{tabular}

The numerical algorithm used to approximate the Markov-perfect equilibrium in each case is a variant of a standard projection method. First, define a grid over $K$. Second, make initial guesses for the value of the functions $\mathcal{H}, \mathcal{N}$ and $\mathcal{G}$ at each gridpoint. The number of unknowns is thus three times the number of gridpoints. Third, solve a system of equations, which includes the two firstorder conditions of the agent's problem and the GEE from the government's problem, evaluated at all the gridpoints. Thus, the number of equations is three times the number of gridpoints. Since some of the equations include variables evaluated at $K^{\prime}$, we need to interpolate the values of policy functions between gridpoints; for this, I use cubic splines. Hence, for each update in the guess, the splines are also updated. To solve the equilibrium I use 50 gridpoints. To verify the approximation, I evaluate the resulting functions at 1,000 gridpoints within the grid end-points and take the sum of squared residuals of the equations used. As a reference, using benchmark parameters, the sum of squared residuals for the GEE in each case is $8 e^{-12}$ and $3 e^{-11}$.

All welfare calculations conducted below are done in terms of private-good consumption equivalent compensation. Consider two different economies (which share preference parameters), $a$ and $b$, and let $\zeta(K)$ be the permanent fraction of private-good consumption that an agent would be willing to give up in order to be indifferent between staying in economy $a$ and switching to economy $b$, for any level of capital $K$. Given the assumptions on preferences, the corresponding welfare measure is defined as

$$
\zeta(K) \equiv \exp \left\{\frac{(1-\beta)\left(\mathcal{V}^{b}(K)-\mathcal{V}^{a}(K)\right)}{\alpha_{c}}\right\}-1 .
$$

\subsection{Steady state}

Table 2 shows the steady state statistics at benchmark parameters. As a reference, the table includes the statistics for the first-best (i.e., with lump-sum taxes) and the Ramsey planner (full intertemporal commitment) long-run allocations. ${ }^{11}$

Relative to the first-best, both Markov taxation cases exhibit too little capital and labor, which is a typical result in models with linear income taxes. When the government is endowed with within-period commitment (i.e., moves first), the provision of public goods is inefficiently low. In contrast, when the government lacks within-period commitment, the provision of public goods is too high. In the latter case, the government does not internalize the effect of taxes on the labor supply, so it implements a higher tax rate - and therefore, higher public good provision - than when

\footnotetext{
${ }^{11}$ See Appendix D for a formulation and characterization of the Ramsey problem. Klein et al. (2008) provide a thorough comparison between Ramsey and Markov-perfect policies, so I omit a similar analysis here.
} 
Table 2: Steady State Statistics

\begin{tabular}{|l|c|c|c|c|}
\hline & First-Best & $\begin{array}{c}\text { Ramsey } \\
\text { Planner }\end{array}$ & $\begin{array}{c}\text { Within-Period } \\
\text { Commitment }\end{array}$ & $\begin{array}{c}\text { No Within-Period } \\
\text { Commitment }\end{array}$ \\
\hline$K / Y$ & 2.959 & 2.306 & 2.449 & 2.276 \\
$G / Y$ & 0.254 & 0.259 & 0.205 & 0.271 \\
$C / G$ & 2.008 & 2.145 & 2.923 & 2.021 \\
$K$ & 1.906 & 0.966 & 1.063 & 0.946 \\
$N$ & 0.350 & 0.262 & 0.262 & 0.262 \\
$\tau$ & - & 0.281 & 0.223 & 0.293 \\
\hline
\end{tabular}

it can commit at the beginning of the period. The fact that public good provision ends up being too high follows from the ways the government internalizes all other wedges, as we shall analyze below.

\subsection{Policy and welfare}

Figure 1 shows policy distortions, as functions of the aggregate capital stock. Wedges are displayed as ratios, $\frac{\beta u_{c}^{\prime}\left(F_{K}^{\prime}+1-\delta\right)}{u_{c}}, \frac{u_{c} F_{N}}{u_{\ell}}$ and $\frac{u_{g}}{u_{c}}$, thus providing a comparable measure of deviation from the first-best, where they would all be equal to one. Recall that governments internalize distortions created today, as a result of current policy, and tomorrow, as a result of future policy, which in turn is affected by current capital accumulation - see equations (8) and (10).

All three distortion ratios are larger than one when the government can commit within the period. The government internalizes all wedges and thus, smoothes distortions across margins. When the government lacks within-period commitment, it no longer internalizes the current distortion on the consumption-leisure margin, $u_{c} F_{N}-u_{\ell}$. Thus, to compensate for all the wedges it cannot directly control, i.e., the intertemporal distortion, $-u_{c}+\beta u_{c}^{\prime}\left(F_{K}^{\prime}+1-\delta\right)$, and future distortions $u_{c}^{\prime} F_{N}^{\prime}-u_{\ell}^{\prime}$ and $u_{g}^{\prime}-u_{c}^{\prime}$, the government reduces the current wedge between private and public goods consumption, $u_{g}-u_{c}$. The result is higher tax rates and public good provision.

In both cases, taxes and the provision of public goods are increasing in the capital stock. When the government cannot commit within the period, tax rates increase faster with capital since the distortion on the labor market is not internalized - see left panel of Figure 2. Thus, as capital increases, $u_{g}-u_{c}$ decreases and eventually becomes negative, counterbalancing all other (future) distortions the government cannot directly control. Higher tax rates imply that the intertemporal wedge, $-u_{c}+\beta u_{c}^{\prime}\left(F_{K}^{\prime}+1-\delta\right)$, although qualitatively similar, is larger without within-period commitment.

The right panel of Figure 2 shows the welfare implications of losing within-period commitment. Using the definition above, $\zeta(K)$ measures the permanent fraction of private-good consumption that an agent would be willing to give up in order to be indifferent between staying in an economy with within-period commitment (economy $a$ ) and switching to an environment without (economy $b$ ). For the range of capital levels displayed in the chart, there is a welfare gain from losing the ability to commit within the period. If we were to start at the steady state in the economy with 
Figure 1: Policy Wedges
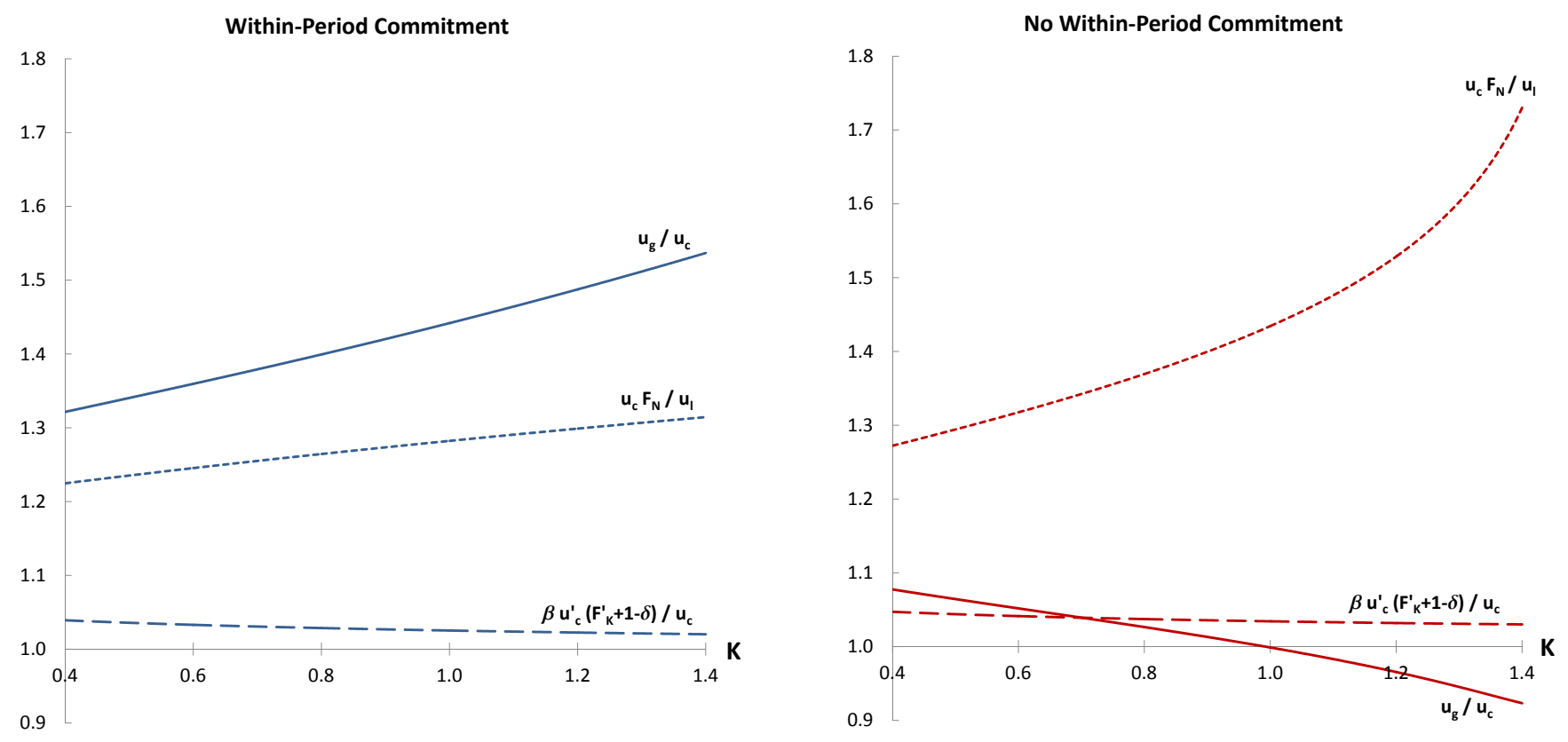

within-period commitment, the welfare gain would be equivalent to a permanent increase in private consumption of $0.52 \%$. This is a result often found in second-best economies, in which an additional friction compensates for other inefficiencies. In this case, not internalizing labor market distortions implies a higher public good provision, which brings welfare closer to the first-best. Welfare gains are decreasing in the capital stock, since the cost of higher tax rates increasingly erode the gains from larger public good consumption. The right panel of Figure 1 shows how, without within-period commitment, the $u_{c} F_{N}-u_{\ell}$ wedge rises at an increasing rate with capital, i.e., the non-internalized consumption-leisure distortion is increasing and convex in the tax rate.

There are three critical elements determining the welfare properties of losing within-period commitment, which are dealt with in the remaining sections, one at a time. First, how the tax base varies with the capital stock affects the slope of the tax function, and thus, the magnitude of distortions created by linear taxation. An important institutional variable in this respect is the capital depreciation allowance, which affects taxable income. Second, how much the government with within-period commitment is undersupplying the public good has a direct implication on the gains from ignoring the consumption-leisure wedge in order to correct the public good distortion. Third, the costs of ignoring the distortion created by taxation on the labor supply depend fundamentally on its elasticity. A less elastic labor supply would bring closer the policies implemented by governments that internalize or ignore the consumption-leisure wedge. 
Figure 2: Policy and Welfare
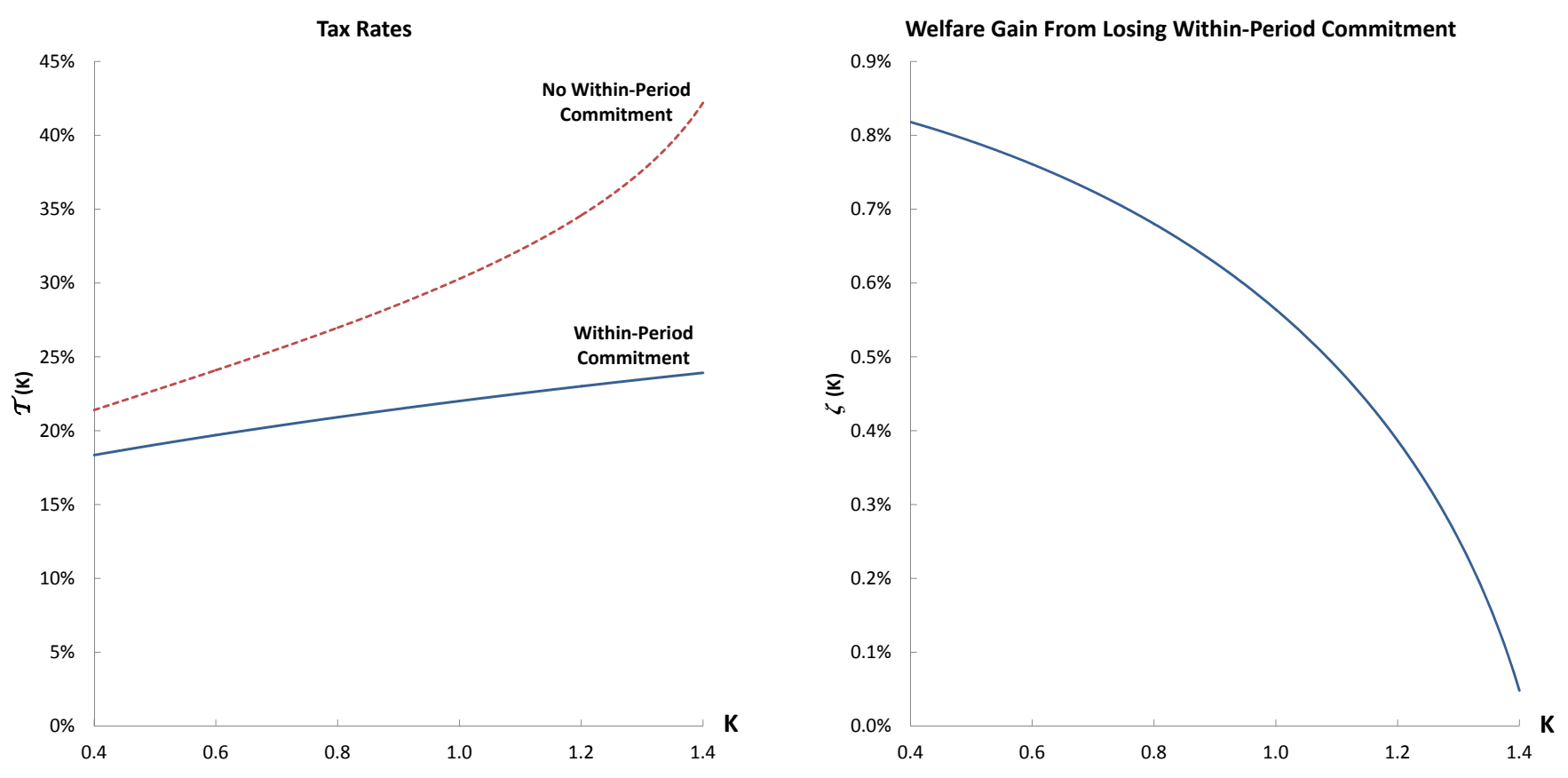

\subsection{Policy experiment: varying capital depreciation allowance}

Deductions to taxable income reduce the tax base and therefore, imply higher tax rates to finance a given level of expenditure. Hence, tax deductions have a direct effect on the magnitude of policy distortions and the welfare properties of institutional reform. In this paper, the only tax deduction is a proportion $\theta$ of capital depreciation. As a reference, $\theta$ in the U.S., measured as described above, has fluctuated between roughly 34\% and 51\% (averaging 42\%) since 1962.

The left panel of Figure 3 displays steady state tax rates as a function of $\theta$, under the two Markov-perfect taxation regimes considered. As we can see, the steady state tax rate without within-period commitment grows at a faster rate with $\theta$ than when the government moves-first. As the tax base decreases with a larger deduction, public good provision would decrease if tax rates were left the same. This effect provides an incentive for higher tax rates, regardless of the degree of commitment. Since a government lacking within-period commitment does not internalize the distortion of higher taxes on the current labor supply, it increases taxes more.

As shown in the right panel of Figure 3, varying $\theta$ has important welfare implications. If the government can commit within the period, then the best policy is to increase the capital depreciation allowance up to its maximum. The main reason is that a higher capital depreciation allowance mitigates the intertemporal (savings) distortion, which results in a wealthier economy. Relative to the benchmark steady state, a reform that increases $\theta$ to $100 \%$ yields gains equivalent to a permanent increase in consumption of $0.52 \%$. Note that this gain is the same as that of losing within-period commitment, as analyzed in the previous section. 
Figure 3: Effects of Varying Capital Depreciation Allowance
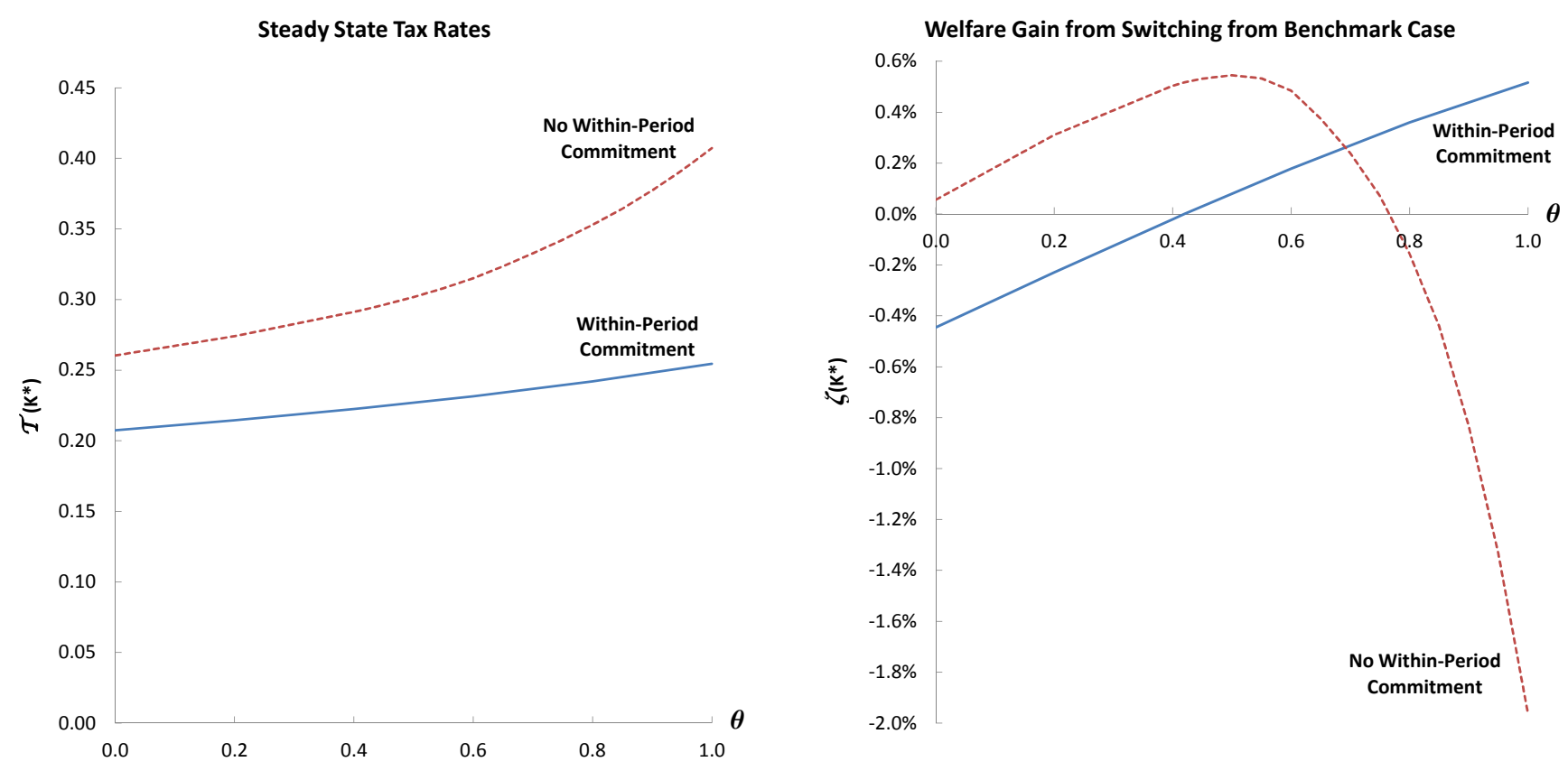

Note: Welfare is measured at the steady state of the economy with within-period commitment.

If the government does not have within-period commitment, then the optimal value for $\theta$ is close to benchmark. Setting $\theta$ to $50 \%$ implies a welfare gain of $0.54 \%$ in consumption equivalent terms, relative to the benchmark steady state. Thus, if we start with an economy without withinperiod commitment, the gains from moving $\theta$ from its benchmark value are very small: roughly worth $0.02 \%$ of consumption. However, varying $\theta$ substantially may imply big losses. For example, relative to benchmark, losing within-period commitment and setting $\theta$ to $100 \%$ implies a loss equivalent to a permanent reduction in consumption of about $2 \%$. These calculations provide a good example of how assuming extreme values of $\theta$ (i.e., either zero or one) can lead to misleading welfare results.

\subsection{Lack of commitment and the size of government}

So far, the working assumption has been that the U.S. postwar economy resembles the Markovperfect equilibrium with within-period commitment. Alternatively, we could hypothesize that the U.S. is best represented by the economy without within-period commitment. As Table 2 readily shows, government size is the main difference between the steady states of these two cases. An alternative thought experiment would then involve lowering $\alpha_{g}$ so that the public good provision for the case with no within-period commitment matches the data. Thus, considering the welfare gains from obtaining within-period commitment is equivalent to studying the effects of a smaller 
government. For the benchmark calibration, the gains from losing within-period commitment come mainly from correcting the inefficient provision of public goods. It follows that welfare differences across regimes would be smaller if policy distortions were not too high to begin with.

Suppose then that the U.S. economy is explained by the case without within-period commitment. This involves a small change in preference parameters: lowering $\alpha_{g}$ from 0.130 to 0.095. Table 3 displays the corresponding steady state statistics. As we can see, the economy without within-period commitment now features the same steady state statistics as the benchmark economy in Table 2.

Table 3: Steady State Statistics when $\alpha_{g}=0.095$

\begin{tabular}{|l|c|c|c|c|}
\hline & First-Best & $\begin{array}{c}\text { Ramsey } \\
\text { Planner }\end{array}$ & $\begin{array}{c}\text { Within-Period } \\
\text { Commitment }\end{array}$ & $\begin{array}{c}\text { No Within-Period } \\
\text { Commitment }\end{array}$ \\
\hline$K / Y$ & 2.959 & 2.459 & 2.547 & 2.450 \\
$G / Y$ & 0.198 & 0.201 & 0.167 & 0.205 \\
$C / G$ & 2.858 & 2.992 & 3.764 & 2.928 \\
$K$ & 1.779 & 1.070 & 1.132 & 1.064 \\
$N$ & 0.327 & 0.262 & 0.263 & 0.262 \\
$\tau$ & - & 0.219 & 0.183 & 0.223 \\
\hline
\end{tabular}

Note: All other parameters are at benchmark.

The differences between the two Markov taxation economies are still significant, but much less pronounced than in Table 2. For example, for the benchmark parameterization, steady state tax rates differed by 7 percentage points. Now, with a lower optimal supply of the public good, tax rates differ by 4 percentage points. Naturally, the welfare differences across environments are smaller as well. Starting from the steady state of the economy without within-period commitment, the loss from obtaining this commitment ability is equivalent to a permanent decrease in consumption of $0.33 \%$. Recall than in the benchmark case, the gain from losing within-period commitment was $0.52 \%$, which is significantly higher. Another important difference between parameterizations, is that the welfare measure as a function of capital, $\zeta(K)$, becomes flatter as we lower $\alpha_{g}$.

We can revisit the policy experiment of varying $\theta$, using this alternative benchmark. Figure 4 shows the effects of varying $\theta$ on steady state taxes and welfare, keeping the same vertical axis as in Figure 3, for comparison with the results in the previous section.

As argued above, the effects of institutional reforms are now less dramatic since a lower $\alpha_{g}$ implies the Markov taxation economies are closer to the optimal allocation. When the government can commit within a period, the best policy is still to allow all of the capital depreciation to be deducted from taxable income. Relative to the alternative benchmark, gaining the ability to commit within a period and setting $\theta=1$ has no effect on welfare. This is congruent with the result in the previous section, for the benchmark case, where the gain from losing within-period commitment was basically equivalent to the gain of setting the depreciation allowance to $100 \%$.

If the U.S. economy is described by the model where the government cannot commit within the period then welfare would improve if the depreciation allowance were increased. Setting $\theta$ to $90 \%$ 
Figure 4: Effects of Varying Capital Depreciation Allowance when $\alpha=0.095$
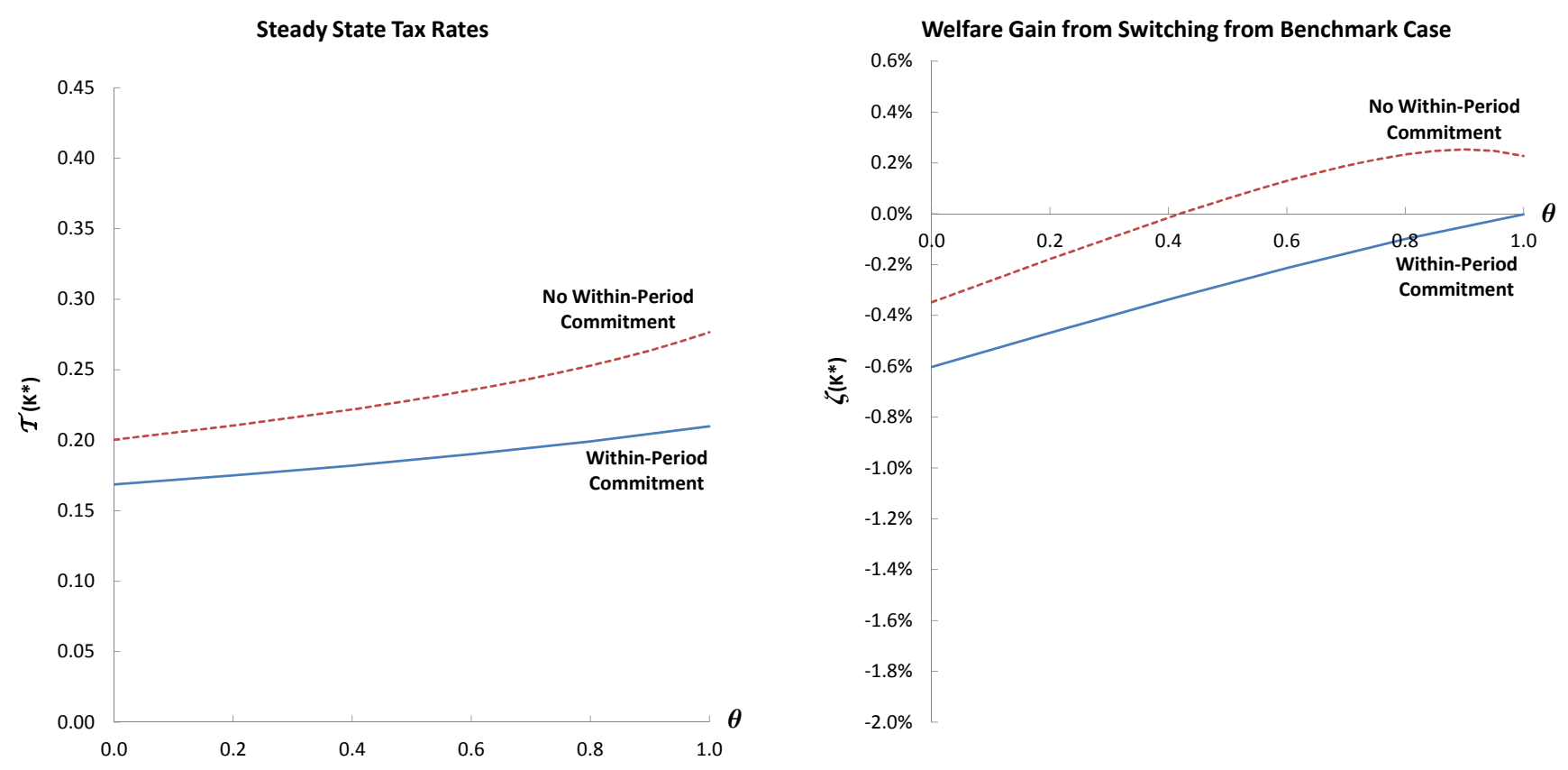

Note: Welfare is measured at the steady state of the economy that lacks within-period commitment.

would increase welfare by $0.25 \%$ in consumption equivalent compensation terms. Note that going all the way to $100 \%$ would still be beneficial relative to benchmark, although marginally worse than the optimal choice.

\subsection{Alternative specifications}

A more general specification for the utility function could be:

$$
u(c, 1-n, G)=\alpha\left(1-\alpha_{g}\right) \ln c+\frac{(1-\alpha)\left(1-\alpha_{g}\right)(1-n)^{1-\chi_{\ell}}}{1-\chi_{\ell}}+\frac{\alpha_{g} G^{1-\chi_{g}}}{1-\chi_{g}},
$$

where $\chi_{\ell}$ would determine the labor-supply elasticity and thus affect the magnitude of the consumptionleisure wedge, whereas $\chi_{g}$ would determine the elasticity of intertemporal substitution for the public good. In the benchmark case, we assumed $\chi_{\ell}=\chi_{g}=1$.

Table 4 shows the effects of recalibrating the benchmark economy assuming $\chi_{\ell}=2$. The only other parameters that change are $\alpha$ and $\alpha_{g}$. As we can see, the two Markov taxation economies resemble each other more than in the benchmark parameterization.

When the government cannot commit within the period, a less elastic labor supply implies a lower cost from tomorrow's consumption-leisure wedge, which results in lower incentives to increase 
Table 4: Steady State Statistics when $\chi_{\ell}=2, \alpha=0.367, \alpha_{g}=0.147$

\begin{tabular}{|l|c|c|c|c|}
\hline & First-Best & $\begin{array}{c}\text { Ramsey } \\
\text { Planner }\end{array}$ & $\begin{array}{c}\text { Within-Period } \\
\text { Commitment }\end{array}$ & $\begin{array}{c}\text { No Within-Period } \\
\text { Commitment }\end{array}$ \\
\hline$K / Y$ & 2.959 & 2.334 & 2.449 & 2.337 \\
$G / Y$ & 0.244 & 0.249 & 0.205 & 0.248 \\
$C / G$ & 2.129 & 2.266 & 2.919 & 2.281 \\
$K$ & 1.771 & 0.983 & 1.061 & 0.985 \\
$N$ & 0.325 & 0.262 & 0.262 & 0.262 \\
$\tau$ & - & 0.270 & 0.224 & 0.269 \\
\hline
\end{tabular}

Note: All other parameters are at benchmark.

public good provision to counterbalance distortions. Thus, taxes and public good provision are not as high as in the benchmark parameterization. The welfare gains from losing commitment are similar in steady state, $0.54 \%$, but the profile in terms of capital is much flatter. In other words, with a less elastic labor supply, the welfare gains from losing within-period commitment are more consistent across different levels of capital.

Empirical estimates for the value of $\chi_{g}$ center around unity, as in the benchmark parameterization. ${ }^{12}$ Since, as shown above, the size of government (i.e., the value of $\alpha_{g}$ ) affects some of the results, it is useful to explore the effects of varying the elasticity of intertemporal substitution of the public good. Table 5 recalibrates the economy assuming that $\chi_{g}=1.5$ and adjusting $\alpha_{g}$ appropriately, so that the economy with within-period commitment is kept observationally equivalent with respect to the benchmark parameterization.

Table 5: Steady State Statistics when $\chi_{g}=1.5, \alpha_{g}=0.042$

\begin{tabular}{|l|c|c|c|c|}
\hline & First-Best & $\begin{array}{c}\text { Ramsey } \\
\text { Planner }\end{array}$ & $\begin{array}{c}\text { Within-Period } \\
\text { Commitment }\end{array}$ & $\begin{array}{c}\text { No Within-Period } \\
\text { Commitment }\end{array}$ \\
\hline$K / Y$ & 2.959 & 2.348 & 2.451 & 2.340 \\
$G / Y$ & 0.218 & 0.244 & 0.204 & 0.246 \\
$C / G$ & 2.506 & 2.334 & 2.933 & 2.298 \\
$K$ & 1.822 & 0.994 & 1.064 & 0.989 \\
$N$ & 0.335 & 0.262 & 0.262 & 0.262 \\
$\tau$ & - & 0.264 & 0.223 & 0.268 \\
\hline
\end{tabular}

Note: All other parameters are at benchmark.

With a lower elasticity of intertemporal substitution for public goods (and a correspondingly smaller $\alpha_{g}$ ), the first-best supply of public goods is lower than in the benchmark parameterization. Thus, the cost of undersupplying public goods in the Markov-perfect equilibrium with within-period

\footnotetext{
${ }^{12}$ For example, see Amano and Wirjanto (1997) and Nieh and wu Ho (2006).
} 
commitment is not as severe. Still, the welfare gains from losing within-period commitment are similar to the benchmark, about $0.54 \%$ of period consumption.

\section{Concluding Remarks}

A general, albeit not altogether novel, lesson is that the welfare properties of policy depend on the margins the government perceives as being distorted. In some cases, correcting certain distortions while ignoring others may improve welfare. Varying the degree of commitment is one way to alter the distortions being internalized by the government.

When a government can only commit to policies within a period and is restricted to follow a balanced budget rule, it provides an inefficiently low level of public goods. If it loses the ability to commit within the period then it no longer internalizes policy distortions on current factor markets. The government then mitigates the private-public goods distortion by increasing taxes and public good provision. This new policy may, in some cases, improve welfare.

For the calibrated economies presented in this paper, the potential welfare gains from losing within-period commitment are modest, about half a percent of yearly consumption. Similar gains can be obtained, if instead, capital depreciation were allowed to be fully deducted from taxable income. However, depending on the details of the underlying economy and which other reforms are being enacted simultaneously, loss of within-period commitment may potentially lead to substantial welfare losses. 


\section{References}

Amano, R. A. and Wirjanto, T. S. (1997), 'Intratemporal substitution and government spending', The Review of Economics and Statistics 79(4), 605-609.

Azzimonti, M., Sarte, P.-D. and Soares, J. (2009), 'Distortionary taxes and public investment when government promises are not enforceable', Journal of Economic Dynamics and Control 33(9), 1662-1681.

Bohn, H. and Inman, R. P. (1996), 'Balanced-budget rules and public deficits: evidence from the u.s. states', Carnegie-Rochester Conference Series on Public Policy 45(1), 13-76.

Chari, V. V. and Kehoe, P. J. (1990), 'Sustainable plans', The Journal of Political Economy 98(4), 784-802.

Debortoli, D. and Nunes, R. (2010), 'Fiscal policy under loose commitment', Journal of Economic Theory 145, 1005-1032.

Greenwood, J., Hercowitz, Z. and Huffman, G. W. (1988), 'Investment, capital utilization, and the real business cycle', American Economic Review 78, 402-417.

Guo, J.-T. and Lansing, K. J. (1997), 'Tax structure and welfare in a model of optimal fiscal policy', Federal Reserve Bank of Cleveland Economic Review 33(1), 11-23.

Guo, J.-T. and Lansing, K. J. (1999), 'Optimal taxation of capital income with imperfectly competitive product markets', Journal of Economic Dynamics and Control 23, 967-995.

Judd, K. L. (1998), Numerical Methods in Economics, The MIT Press, Cambridge.

Klein, P., Krusell, P. and Ríos-Rull, J.-V. (2008), 'Time-consistent public expenditures', The Review of Economic Studies 75(3), 789-808.

Klein, P. and Ríos-Rull, J.-V. (2003), 'Time-consistent optimal fiscal policy', International Economic Review 44(4), 1217-1246.

Krusell, P., Martin, F. M. and Ríos-Rull, J.-V. (2006), Time-consistent debt. Mimeo.

Krusell, P. and Smith, A. (2003), 'Consumption-savings decisions with quasi-geometric discounting', Econometrica 71(1), 365-375.

Martin, F. M. (2009), 'A positive theory of government debt', Review of Economic Dynamics 12(4), 608-631.

Martin, F. M. (2010), 'Markov-perfect capital and labor taxes', Journal of Economic Dynamics and Control 34(3), 503-521.

Maskin, E. and Tirole, J. (2001), 'Markov perfect equilibrium', Journal of Economic Theory 100, 191-219.

Nieh, C.-C. and wu Ho, T. (2006), 'Does the expansionary government spending crowd out the private consumption?: Cointegration analysis in panel data', The Quarterly Review of Economics and Finance 46(1), 133-148. 
Ortigueira, S. (2006), 'Markov-perfect optimal taxation', Review of Economic Dynamics 9, 153-178.

Ortigueira, S., Pereira, J. and Pichler, P. (2012), Markov-perfect optimal fiscal policy: The case of unbalanced budgets. Mimeo.

Pecorino, P. (1993), 'Tax structure and growth in a model with human capital', Journal of Public Economics 52, 251-271.

Phelan, C. and Stacchetti, E. (2001), 'Sequential equilibria in a Ramsey tax model', Econometrica 69(6), 1491-1518.

Stockman, D. R. (2001), 'Balanced-budget rules: Welfare loss and optimal policies', Review of Economic Dynamics 4, 438-459.

Stokey, N. L. and Rebelo, S. (1995), 'Growth effects of flat-rate taxes', The Journal of Political Economy 103(3), 519-550.

Taylor, J. B. (2011), 'An empirical analysis of the revival of fiscal activism in the 2000s', Journal of Economic Literature 49(3), 686-702.

Turnovsky, S. J. and Brock, W. A. (1980), 'Time consistency and optimal government policies in perfect foresight equilibrium', Journal of Public Economics 13, 183-212.

Zhu, X. (1995), 'Endogenous capital utilization, investor's effort, and optimal fiscal policy', Journal of Monetary Economics 36, 655-677. 


\section{A Derivation of $\mathcal{V}_{K}$}

\section{A.1 Government-moves-first}

Totally differentiating $\mathcal{V}(K)$ - expression (ii) in Definition 1 - with respect to $K$ implies

$$
\mathcal{V}_{K}=u_{c}\left(F_{K}+1-\delta\right)+\left(-u_{c}+\beta \mathcal{V}_{K}^{\prime}\right) \mathcal{H}_{K}+\left(u_{c} F_{N}-u_{\ell}\right) \mathcal{N}_{K}+\left(-u_{c}+u_{g}\right) \mathcal{G}_{K}
$$

Using the first-order conditions of the government's problem, we can rewrite the condition above as follows:

$$
\mathcal{V}_{K}=u_{c}\left(F_{K}+1-\delta\right)-\lambda\left(\Sigma_{K^{\prime}} \mathcal{H}_{K}+\Phi_{N} \mathcal{N}_{K}+\Phi_{G} \mathcal{G}_{K}\right)-\mu\left(\Psi_{K^{\prime}} \mathcal{H}_{K}+\Psi_{N} \mathcal{N}_{K}+\Psi_{G} \mathcal{G}_{K}\right)
$$

In a Markov-perfect equilibrium, totally differentiating (6) and (7) with respect to $K$ implies:

$$
\begin{aligned}
\Phi_{K}+\Sigma_{K^{\prime}} \mathcal{H}_{K}+\Phi_{N} \mathcal{N}_{K}+\Phi_{G} \mathcal{G}_{K} & =0 \\
\Psi_{K}+\Psi_{K^{\prime}} \mathcal{H}_{K}+\Psi_{N} \mathcal{N}_{K}+\Psi_{G} \mathcal{G}_{K} & =0
\end{aligned}
$$

Using the expressions above, we obtain $\mathcal{V}_{K}=u_{c}\left(F_{K}+1-\delta\right)+\lambda \Phi_{K}+\mu \Psi_{K}$.

\section{A.2 Simultaneous actions}

We follow the same procedure. Note that the first-order conditions of the government's problem are different. Thus, in this case, we obtain:

$$
\mathcal{V}_{K}=u_{c}\left(F_{K}+1-\delta\right)+\left(u_{c} F_{N}-u_{\ell}\right) \mathcal{N}_{K}-\lambda\left(\Sigma_{K^{\prime}} \mathcal{H}_{K}+\Phi_{G} \mathcal{G}_{K}\right) .
$$

In a Markov-perfect equilibrium, totally differentiating (9) with respect to $K$ implies

$$
\Phi_{K}+\Sigma_{K^{\prime}} \mathcal{H}_{K}+\Phi_{N} \mathcal{N}_{K}+\Phi_{G} \mathcal{G}_{K}=0
$$

Thus, $\mathcal{V}_{K}=u_{c}\left(F_{K}+1-\delta\right)+\left(u_{c} F_{N}-u_{\ell}\right) \mathcal{N}_{K}+\lambda\left(\Phi_{K}+\Phi_{N} \mathcal{N}_{K}\right)$.

\section{B Analytical solutions}

Under suitable assumptions, we can show the existence of differentiable Markov-perfect equilibria by solving analytically the problems specified in Section 2. The algorithm for finding analytical solutions is as follows: (i) assume $T<\infty$ and use the fact that $K_{T+1}=0$ to solve the problem of the government using backwards induction; (ii) use the finite-horizon solution for the initial period and take the limit as the horizon goes to infinity to obtain stationary policy functions. An equilibrium found this way is the limit of finite horizon equilibria, which ensures that we are comparing equilibria of the same type. The algebraic details of the backward iteration are omitted here for brevity, but the procedure is described in Martin (2010).

Consider the following assumptions, which are standard for obtaining analytical solutions in this type of environment. 
Assumption $1 u(c, 1-n, G)=\alpha_{c} \ln c+\alpha_{\ell} \ln (1-n)+\alpha_{g} \ln G, \alpha_{c}, \alpha_{\ell}, \alpha_{g}>0$.

Assumption $2 F(K, N)=K^{\gamma} N^{1-\gamma}, \gamma \in(0,1)$.

Assumption $3 \delta=1, \theta=0$.

Proposition 1 Suppose Assumptions 1, 2 and 3 hold. Then, the Markov-perfect equilibria with and without within-period commitment are equivalent and characterized by the following functions:

$$
\begin{aligned}
\mathcal{H}(K) & =\beta \gamma(1-\rho) K^{\gamma} N^{1-\gamma} \\
\mathcal{N}(K) & =N \\
\mathcal{G}(K) & =\rho K^{\gamma} N^{1-\gamma}
\end{aligned}
$$

where $N \equiv\left[1+\frac{\alpha_{\ell}(1-\beta \gamma)}{\alpha_{c}(1-\gamma)}\right]^{-1}$ and $\rho \equiv \frac{\alpha_{g}(1-\beta \gamma)}{\alpha_{c}+\alpha_{g}}$.

Proof. It is straightforward to verify that these functions satisfy the equilibrium conditions for the respective cases, i.e., the two first-order conditions from the agent's problem and the GEE from the government's problem.

Under Assumptions 1-3, which allow for a closed-form solution, both environments analyzed Section 2 yield identical equilibria. The reason is that under these assumptions, labor is not a function of capital, and therefore, it does not matter whether the government internalizes the effects of its policy on labor decisions or not.

Other functional forms may yield analytical solutions that are different for each environment. For example, we could follow Greenwood et al. (1988) and assume: $\alpha_{c} \ln \left(c-\frac{\alpha_{n} n^{1+\chi}}{1+\chi}\right)+\alpha_{g} G$. For a three-period economy, since in this case labor always depends on the capital stock, one can show that the analytical solutions differ between environments. Further increasing the time horizon leads to increasingly intractable solutions. ${ }^{13}$

\section{Alternative specifications for simultaneous actions}

\section{C.1 Simultaneous actions with consumption as residual}

Here, we consider the case when the household decides savings and labor at the same time as the government sets the tax rate and thus, consumption is determined as a residual. In other words, if the current government were to deviate from the expected tax rule, the households would not know their consumption until after observing the tax rate. The problem of the current government can be written as

$$
\max _{G} u(F(K, \mathcal{N}(K))+(1-\delta) K-G-\mathcal{H}(K), 1-\mathcal{N}(K), G)+\beta \mathcal{V}(\mathcal{H}(K)) .
$$

\footnotetext{
${ }^{13}$ I thank an anonymous referee for suggesting that GHH preferences could also yield analytical solutions. The calculations for the case with three periods are available upon request. I would not discard the possibility that the analytical solutions may converge to manageable expressions in the long-run.
} 
Notice that the current government takes current savings and labor as given, but can affect current consumption. Since savings are not affected by current government actions, the problem of the government is static.

Definition 3 Alternative Case 1. When households and the government move simultaneously, and consumption is determined residually at the end of the period, a Markov-perfect equilibrium is a set of functions $\{\mathcal{H}, \mathcal{N}, \mathcal{G}, \mathcal{V}\}: \mathbb{R}_{+} \rightarrow \mathbb{R}_{+} \times[0,1] \times \mathbb{R}_{+} \times \mathbb{R}$, such that for all $K>0$ :

(i) $\mathcal{G}(K)=\operatorname{argmax}_{G} u(F(K, \mathcal{N}(K))+(1-\delta) K-G-\mathcal{H}(K), 1-\mathcal{N}(K), G)+\beta \mathcal{V}(\mathcal{H}(K))$;

(ii) $\Phi(K, \mathcal{H}(K), \mathcal{H}(\mathcal{H}(K)), \mathcal{N}(K), \mathcal{N}(\mathcal{H}(K)), \mathcal{G}(K), \mathcal{G}(\mathcal{H}(K)))=0$

(iii) $\Psi(K, \mathcal{H}(K), \mathcal{N}(K), \mathcal{G}(K))$;

(iv) $\mathcal{V}(K)=u(F(K, \mathcal{N}(K))+(1-\delta) K-\mathcal{H}(K)-\mathcal{G}(K), 1-\mathcal{N}(K), \mathcal{G}(K))+\beta \mathcal{V}(\mathcal{H}(K))$.

The first-order condition of the government's problem implies

$$
u_{c}=u_{g}
$$

This is the same condition that a government with access to lump-sum taxes would implement. Thus, when consumption is determined as a residual, government policy eliminates the wedge between private and public good consumption. However, the economy is not at the first-best; we still have the wedges between consumption and leisure, and current and future consumption. Note that under special assumptions, a government with full intertemporal commitment would implement the same long-run allocation-see Proposition 3 in Appendix D.

\section{C.2 Simultaneous actions with savings as residual}

Now assume that households choose consumption and labor at the same time as the government chooses the tax rate. Thus, savings are left as a residual. This environment corresponds to the one analyzed by Ortigueira (2006). The problem of the current government can be written as

$$
\max _{G} u(C(K), 1-\mathcal{N}(K), G)+\beta \mathcal{V}(F(K, N(K)+(1-\delta) K-G-C(K)) .
$$

In this case, the problem of the government is dynamic, since policy affects capital accumulation.

Definition 4 Alternative Case 2. When households and the government move simultaneously, and savings are determined residually at the end of the period, a Markov-perfect equilibrium is a set of functions $\{\mathcal{C}, \mathcal{H}, \mathcal{N}, \mathcal{G}, \mathcal{V}\}: \mathbb{R}_{+} \rightarrow \mathbb{R}_{+}^{2} \times[0,1] \times \mathbb{R}_{+} \times \mathbb{R}$, such that for all $K>0$ :

(i) $\mathcal{G}(K)=\operatorname{argmax}_{G} u(C(K), 1-\mathcal{N}(K), G)+\beta \mathcal{V}(F(K, N(K)+(1-\delta) K-G-C(K))$;

(ii) $\Phi(K, \mathcal{H}(K), \mathcal{H}(\mathcal{H}(K)), \mathcal{N}(K), \mathcal{N}(\mathcal{H}(K)), \mathcal{G}(K), \mathcal{G}(\mathcal{H}(K)))=0$;

(iii) $\Psi(K, \mathcal{H}(K), \mathcal{N}(K), \mathcal{G}(K))$; 
(iv) $F(K, \mathcal{N}(K))+(1-\delta) K-\mathcal{C}(K)-\mathcal{G}(K)-\mathcal{H}(K)=0$;

(v) $\mathcal{V}(K)=u(F(K, \mathcal{N}(K))+(1-\delta) K-\mathcal{H}(K)-\mathcal{G}(K), 1-\mathcal{N}(K), \mathcal{G}(K))+\beta \mathcal{V}(\mathcal{H}(K))$

The first-order condition of the government's problem is

$$
u_{g}-\beta \mathcal{V}_{K}^{\prime}=0
$$

The envelope condition implies

$$
\mathcal{V}_{K}=u_{c} \mathcal{C}_{K}-u_{\ell} \mathcal{N}_{K}+\beta \mathcal{V}_{K}^{\prime}\left(F_{K}+1-\delta+F_{N} \mathcal{N}_{K}-\mathcal{C}_{K}\right),
$$

which after using $u_{g}=\beta \mathcal{V}_{K}^{\prime}$ from (12) implies the following GEE

$$
-u_{g}+\beta u_{g}^{\prime}\left(F_{k}^{\prime}+1-\delta\right)+\beta\left(u_{c}^{\prime}-u_{g}^{\prime}\right) \mathcal{C}_{K}^{\prime}+\beta\left(u_{g}^{\prime} F_{N}^{\prime}-u_{\ell}^{\prime}\right) \mathcal{N}_{K}^{\prime}=0 .
$$

From the resource constraint, $\mathcal{C}_{K}=F_{K}+F_{N} \mathcal{N}_{K}-\mathcal{G}_{K}-\mathcal{H}_{K}$, and thus,

$$
-u_{g}+\beta u_{c}^{\prime}\left(F_{K}^{\prime}+1-\delta\right)+\beta\left(u_{c}^{\prime}-u_{g}^{\prime}\right)\left(\mathcal{G}_{K}^{\prime}+\mathcal{H}_{K}^{\prime}\right)+\beta\left(u_{c}^{\prime} F_{N}^{\prime}-u_{\ell}^{\prime}\right) \mathcal{N}_{K}^{\prime}=0 .
$$

This way of writing the GEE makes all the different cases easier to compare, as they can all be solved in terms of $\{\mathcal{H}, \mathcal{N}, \mathcal{G}\}$ only.

\section{C.3 Analytical solutions}

Proposition 2 Suppose Assumptions 1, 2 and 3 hold. Then, for all $K>0$ the equilibrium policy functions for Alternative Case $i=\{1,2\}$ are:

$$
\begin{aligned}
\mathcal{H}^{i}(K) & =\beta \gamma\left(1-\rho^{i}\right) K^{\gamma} N^{1-\gamma} \\
\mathcal{N}^{i}(K) & =N \\
\mathcal{G}^{i}(K) & =\rho^{i} K^{\gamma} N^{1-\gamma}
\end{aligned}
$$

where $N \equiv\left[1+\frac{\alpha_{\ell}(1-\beta \gamma)}{\alpha_{c}(1-\gamma)}\right]^{-1}, \rho^{1} \equiv \frac{\alpha_{g}(1-\beta \gamma)}{\alpha_{c}+\alpha_{g}(1-\beta \gamma)}$ and $\rho^{2} \equiv \frac{\alpha_{g}(1-\beta \gamma)}{\alpha_{c}+\alpha_{g}(2-\beta \gamma)}$.

Proof. It is straightforward to verify that these functions satisfy the equilibrium conditions for the respective cases, i.e., the two first-order conditions from the agent's problem, the GEE from the government's problem, the resource constraint and the government budget constraint.

\section{C.4 Numerical results}

Table 6 extends Table 2 to include the steady state statistics of the two alternative cases described above. The last line displays the welfare gain from switching from the benchmark economy with within-period commitment. As we can see, the variants without within-period commitment feature very similar steady state statistics. Welfare gains from losing commitment are highest for "Alternative Case 1", since the private-public good distortion is completely eliminated. Note that the consumption equivalent compensation is only 0.004 percentage points higher than in the standard no within-period commitment case. 
Table 6: Steady State Statistics for Benchmark Parameters

\begin{tabular}{|l|c|c|c|c|}
\hline & $\begin{array}{c}\text { Within-Period } \\
\text { Commitment }\end{array}$ & $\begin{array}{c}\text { No Within-Period } \\
\text { Commitment }\end{array}$ & $\begin{array}{c}\text { Alternative } \\
\text { Case 1 }\end{array}$ & $\begin{array}{c}\text { Alternative } \\
\text { Case 2 }\end{array}$ \\
\hline$K / Y$ & 2.449 & 2.276 & 2.272 & 2.273 \\
$G / Y$ & 0.205 & 0.271 & 0.272 & 0.272 \\
$C / G$ & 2.923 & 2.021 & 2.008 & 2.012 \\
$K$ & 1.063 & 0.946 & 0.943 & 0.944 \\
$N$ & 0.262 & 0.262 & 0.262 & 0.262 \\
$\tau$ & 0.223 & 0.293 & 0.295 & 0.294 \\
$\zeta$ & $0.00 \%$ & $0.52 \%$ & $0.52 \%$ & $0.48 \%$ \\
\hline
\end{tabular}

The three cases with lack of within-period commitment become more differentiated as we move towards extreme values for $\theta$. The largest differences occur when $\theta=1$, which implies steady state tax rates of $0.332,0.468$ and 0.407 , for the standard case, alternative case 1 and alternative case 2 , respectively. For this parameterization, switching from within-period commitment to alternative case 1 would imply a welfare gain, whereas switching to the other two cases without within-period commitment would imply (large) welfare losses. These calculations are available upon request.

\section{The Ramsey problem}

Suppose the government can commit at time zero to all future policy decisions, but is subjected to a balanced budget constraint, as in Stockman (2001) and Klein et al. (2008). The problem of the government can be written as follows:

$$
\begin{aligned}
\max _{\left\{K_{t+1}, N_{t}, G_{t}\right\}_{t=0}^{\infty}} \sum_{t=0}^{\infty} \beta^{t}\{ & u\left(F\left(K_{t}, N_{t}\right)+(1-\delta) K_{t}-G_{t}, 1-N_{t}, G_{t}\right) \\
& \left.+\lambda_{t} \Phi\left(K_{t}, K_{t+1}, K_{t+2}, N_{t}, N_{t+1}, G_{t}, G_{t+1}\right)+\mu_{t} \Psi\left(K_{t}, K_{t+1}, N_{t}, G_{t}\right)\right\}
\end{aligned}
$$

given $K_{0}$ and a standard transversality condition. Switching to short-hand notation, the first-order conditions are

$$
\begin{array}{r}
-u_{c, t}+\beta u_{c, t+1}\left(1-\delta+F_{K, t+1}\right)+\beta^{-1} \lambda_{t-1} \Phi_{K^{\prime \prime}, t-1} \\
+\lambda_{t} \Phi_{K^{\prime}, t}+\beta \lambda_{t+1} \Phi_{K, t+1}+\mu_{t} \Psi_{K^{\prime}, t}+\beta \mu_{t+1} \Psi_{K, t+1}=0 \\
u_{c, t} F_{N, t}-u_{\ell, t}+\beta^{-1} \lambda_{t-1} \Phi_{N^{\prime}, t-1}+\lambda_{t} \Phi_{N, t}+\mu_{t} \Psi_{N, t}=0 \\
-u_{c, t}+u_{g, t}+\beta^{-1} \lambda_{t-1} \Phi_{G^{\prime}, t-1}+\lambda_{t} \Phi_{G, t}+\mu_{t} \Psi_{G, t}=0 .
\end{array}
$$


In the long-run, the allocation $\left\{K^{*}, N^{*}, G^{*}, \lambda^{*}, \mu^{*}\right\}$ solves

$$
\begin{aligned}
\Phi\left(K^{*}, K^{*}, K^{*}, N^{*}, N^{*}, G^{*}, G^{*}\right) & =0 \\
\Psi\left(K^{*}, K^{*}, N^{*}, G^{*}\right) & =0 \\
u_{c}^{*}\left(-1+\beta\left(1-\delta+F_{K}^{*}\right)\right)+\lambda^{*}\left(\beta^{-1} \Phi_{K^{\prime \prime}}^{*}+\Phi_{K^{\prime}}^{*}+\beta \Phi_{K}^{*}\right)+\mu^{*}\left(\Psi_{K^{\prime}}^{*}+\beta \Psi_{K}^{*}\right) & =0 \\
u_{c}^{*} F_{N}^{*}-u_{\ell}^{*}+\lambda^{*}\left(\beta^{-1} \Phi_{N^{\prime}}^{*}+\Phi_{N}^{*}\right)+\mu^{*} \Psi_{N}^{*} & =0 \\
-u_{c}^{*}+u_{g}^{*}+\lambda^{*}\left(\beta^{-1} \Phi_{G^{\prime}}^{*}+\Phi_{G}^{*}\right)+\mu^{*} \Psi_{G}^{*} & =0 .
\end{aligned}
$$

The following result relates the steady state of Markov case 1 with the Ramsey long-run allocation (Klein, Krusell and Ríos-Rull, 2008 make a similar observation).

Proposition 3 Under Assumptions 1 and 2, if $\theta=1$ then the long-run Ramsey allocation coincides with the Markov Alternative Case 1 steady state.

Proof. Suppose Assumptions 1 and 2 hold and $\theta=1$. Then, we can verify that $\beta^{-1} \Phi_{G^{\prime}}^{*}+\Phi_{G}^{*}=$ $\Psi_{G}^{*}=0$, so that (18) simplifies to $u_{c}^{*}=u_{g}^{*}$, which is identical to (11). Thus, $\left\{K^{*}, N^{*}, G^{*}\right\}$ is also the steady state of Alternative Case 1. 